World Bank Reprint Series: Number Seventy-four

Graham Pyatt and Jeffrey I. Round

\title{
Social Accounting Matrices for Development Planning
}




\title{
SOCIAL ACCOUNTING MATRICES FOR DEVELOPMENT PLANNING ${ }^{1}$
}

\author{
BY GRAHAM PYAT AND JW IFRF:I I. ROUND \\ World Bank and L'nicersity of Warwick, England
}

\begin{abstract}
The paper reports experience in constructing rocial accounting matrices (SAMs) for three national economies, viz. Iran, Sri Lanka and Swaziland. The SAMs focus particularly on the distribution of income through disaggregati. $n$ of household sector income and outlay accounts consistent, with more conventional disaggregation of production, factors, etc. The SAMs were conceived as an initial step towards understanding income distribution as an inlegral part of the development process and have been developed in parallel with work on planning models. Both the Iran and Sri Lanka SAMs were constructed within the context of the International Labour (Iffice. World Employment Programme: that for Iran was intended as a contribution to the work of the Comprehensive Finiplor ment Strategy Mission to Iran under WEP auspices; while the Sri Lanka SAM was more specifically a research oriented study. The Swaziland study was financed by the Overseas Development Minstry, London as a research activity.

Some learning-by-doing was involved in the sequence of SAMs and the problems encountered, solutions adopted and lessons learned provide the main substance of the paper.
\end{abstract}

\section{INIR()IDU(TI)}

It is well known that accounts for transactions within an economy can be presented in matrix as opposed to double entry format. Such a matrix can be called a social accounting matrix (SAM) and must be square. ${ }^{2}$ Within it each row records the details of receipts by each particular account while the columns (which follow the same ordering as the rows) record the corresponding expenditures. Thus the entry in row $\mathrm{i}$, column $\mathrm{j}$, represents receipts by account $\mathrm{i}$ from account $j$ or, alternatively, expenditures by account $j$ which are paid to account $i$. Within such a general schema, SAMs can take a wide variety of forms, depending on how the constituent accounts are defined. A particular and most important variant is provided by the UN System of National Accounts (SNA) ${ }^{3}$ which has set down guidelines for deriving national income statistics as part of a more comprehensive social accounting matrix approach. It is noteworthy, however, that only a small part of the text of the SNA is directed towards the specific needs of the developing countries, and even then the discussion is downgraded to "suggestions" rather than "guidelines" for implementation. A full implementation of the SNA has frequently been questioned as a statistical priority, as has the need for a SAM approach to macroeconomic information systems. Our view is that the underlying philosophy of the SNA and the SAM approuch is thoroughly appropriate to statistical systems for developing countrics, but that

\footnotetext{
${ }^{1} T$ The views expressed in this papur are those of the authors and should not be attributed to the World Bank or any of its affiliate. We are grateful to Dudley Seers and Stanley Webster for comments on an earlier draft.

${ }^{2}$ Non-square formats can be defined. However, these are always based, conceptually at least, on a square matrix which is the basic format.

${ }^{3}$ United Nations (1968).
} 
some flexibility and a less mechanistic approach are needed for its actual implementation. In particular, we consider detailed disaggregation of factor and household accounts-implying, for example, separate accounts for different types of labour and for different types of household-as an importan $九$ priority. This position is developed in the course of this paper. Meanwhile, there are not many examples of the SAM approach applied to developing countries and our main purpose here is to outline and compare the results of three studies with which we have been associated. These have led to SAMs for Iran in 1970; Sri Lanka, also in 1970; and for Swaziland in 1971-72, ${ }^{4}$ all of which attempt disaggregation of houscholds and/or factors in one form or another. Tables 1, 2 and 4 give a preliminary impression of the results that these studies have yielded. Further detail of each of the studies is provided in the third, fourth and fifth sections of this paper where some of the practical difficulties encountered in our work are described.

Before coming to these studies, in the next section of this paper we discuss some of the reasons for undertaking this work. This is necessary for a number of reasons. One is the contention that the need for data systems derives from concern for quantitative advice on policy; and that the characteristics of such. systems feed back onto the nature of advice that can be offered. Such considerations explain why our studies depart from SNA recommendations in some respects Specifically, the motivation of our work has been the need for an information system to advise on the issues of employment opportunities and income distribution which have challenged the conventional emphasis in macroeconomics on growth per se. This need has been clearly identified by the International Labour Office, World Employment Programme, and implies the view that economic growth is inadequate as a policy objective unless its content, in terms of the living standards of different groups within society, is spelled out. ${ }^{5}$ Acceptance of this position implies that conventional data systems which derive from a preoccupation with aggregate growth or average living standards must also be judged inadequate. Accordingly, we greatly regret the separation of the U.N. SNA from the System of Social and Demographic Statistics ${ }^{6}$ and have made a start in our work toward the integration of the two. Thus in a narrow sense the SINA is inadequate for our purposes. ${ }^{7}$ However, this point is subsidiary to the fact that developments or modifications of the system, such as we have explored, are greatly helped by the underlying system philosophy, that is by the SAM approach. If the SNA is interpreted as having championed this approach, rather than in terms of its specific detail, then we would see it as having a great deal to offer developing countries which they may ill-afford to be without. Meanwhile our three case studies illustrate the feasibility of making progress in this direction.

\footnotetext{
${ }^{4}$ References to sources and methods used in these studies are provided as part of the discussion of each.

${ }^{5}$ See International Labour Office (1976).

${ }^{6}$ See United Nations (1975).

${ }^{7}$ It is noteworthy however that the report "Provisional guidelines on statistics un the distribution of income, consumption, and accumulation", recently issued by the United Nations, proposes ways of integrating household income distribution data and the SNA.
} 


\section{BACK(IROUNI) TO THF: STIIIFIS}

The historical origins of the SNA, going back 300 years, are set out briefly by Stone in his forew rid to a forthcoming book. ${ }^{8}$ Our discussion can start from a more recent event ilamely, the inception in 1960 of work on the Cambridge Growth Project which was initiated by Stone in association with Brown. This work produced the first SAM," as we now know them, as the informuiun system counterpart of early "ersions of the (ambridge (rrowth Model. ${ }^{10}$ At this time the structure of the welfare state in the UK was well cstablished so that questions of employment opportunities and care of the necdy were not pressing. The issues which caused most concern were those of economic growth, or rather a comparative lack of it. The focus of the work was therefore on industrial structure. To carry it through called for various developments on standard input-output analysis so that contributions were forthcoming, such as the RAS method of updating technology matrices and the use of "makc-matrices" to supplement commodity-by-industry specifications of technology." The latter especially is now firmly established in the SNA recommendations.

It is important to emphasize this link between policy, data : nd models because it is essential and permeates our own work. Ir. the SNA the link between data and models is fully explicit and both aspects build on the earlier Cambridge work. Unfortunately, it is in the nature of affairs that the policy applications of the SNA have to be taken largely as read. Much of the complication of the revised SNA seems hardly worthwhile if the purpose is simply to get better estimates of national income. At least some criticisms of it might be muted if it is realized that the purpose is to describe an economy in detail with a view to changes, or to making sure that it remains on course. On this view the heart of the SNA is the model that the data serve to calibrate, in much the same way that the economics of Keynes is the rationale of conventional national accounts. ${ }^{12}$

The links between policy, models and data in our own work explain its special characteristics. The International Labour Office (ILO) World Employment Programme (WEP) sent a comprehsusive employment strategy mission to Colombia in 1970 under the leadership of Dudley Seers. The report of this mission $^{13}$ raised the question of whether its recommendation and those of other such missions could be set in a comprehensive consistency framework. ${ }^{14}$ The next WEP mission-to Sri Lanka this time, and again with Seers as its leader-

\footnotetext{
${ }^{8}$ Pyatt and Roe with L.indley. Round and others (f')rthcoming).

${ }^{9}$ We are advised tha' there are antecedents from work in Norway and the Netherlands dating back to the 1930's and '40s.

${ }^{10}$ See Cambridge, Department of Applied Economics (1962).

${ }^{11}$ See Cambridge, Department of Applied Economics (1962- ), Volumes 1 and 3 for early references on these subjects. The RAS method is subsequently dev'loped by Bacharach (1970). The project has pioneered a number of other contributuns. However, those cited are the ones which have become most firmly established in statistical--as opposed to modeling-- work.

${ }^{12}$ The economics of Karl Marx leads to th: net material product concept, as opposed to national income.

${ }^{13}$ International Lahisur Office (1970).

${ }^{14}$ One early response to this question has been a paper by Thorbecke and Sengupta (1972). Subsequently, Thorbecke has set out his views as part of the evaluation of the first five WEP comprehensive employment strategy missions. See International Labour Office (1973b).
} 
provided an interesting opportunity to pursue the issues for two reasons, One was the fact that Seers has been a pioneer in this field for many years and his national accounts for Zambia for example are a fascinating and unconventional attempt to address the data requirements of a developing country and to reconcile them with what is possible. ${ }^{15}$ From his recent writings ${ }^{16}$ it may be fair to classify Seers as a critic, if not as an opponent of the SNA. However, his unconventional iystem for Zambia can in fact be rearranged as a more or lesss conventional $\ldots 1$, while his criticisms of the SNA can all be embraced by it in its SAM incarnation.

The second factor to make the choice of Sri Lanka propitious for the issues under discussion was that a considerable amount of time and energy had been spent in deriving a credible series of national accounts. ${ }^{17}$ These were complemented by an input-output table estimated by Narapalasingham, who subsequently used these data to build a planning modei of Sri Lanka along the lines of the Cambridge Growth Model. ${ }^{{ }^{*}}$ A particular feature of this work involved experimentation with the effects of income redistribution. As such it was a pioneering effort. The case study of Sri Lanka discussed in the next section was undertaken as part of WEP research in an attempt to resolve some of the issues that this earlier mission had raised. In the interim, however, there was a further WEP country rassion, this time to Iran.

The respective economic circumstances of Sri Lanka and Iran imply that the issues of growth, employment, poverty and income distribution arise in a quite different setting. In Iran a crucial question was, and remains, the extent to which policies for growth might need to be modified in order to do more for the poor, especially in rural areas. The modelling of income distribution questions was therefore important, and a data system which embraced them was needed accordingly. Narapalasingham had been able to avoid this need because his model of Sri Lanka looked only at how a change in income distribution influenced consumer demand, and hence the structure of production. He did not consider how production structure influenced factor payments and hence income distribution. In this sense his model was incomplete. In the Iran context both directions of causality were thought to be crucial. The model and data system were therefore designed to capture them both, otherwise building on earlier work in Sri Lanka. ${ }^{19}$

The need to introduce income distribution into models and social accounts has meant going beyond the realms of the SNA into the province of the UN System of Social and Demographic Statistics. This has raised a number of questions, some of which are touched on in what follows. Meanwhile we have already mentioned our regret that this development of economic and sociei statistics should be separate from the SNA. Our work indicates that it is rela-

\footnotetext{
${ }^{15}$ See Frank (1967) for a discussion of Seers' approach.

${ }^{16}$ Seers $(1975)$.

${ }^{17}$ As part of an earlier (JNI)P planning project.

${ }^{18}$ This work was undertaken as a $\mathrm{Ph} . \mathrm{D}$. thesis under the supervision of Alan Brown. See Narapalasingham (1970).

${ }^{19}$ Apart from the Narapalasingham study some modelling work was undertaken as part of the mission in Sri Lanka. Some of this is reported in II.O (1971), Volume II, Technical Appendix 4.
} 
tively straightforward to integrate aspects of both systems at the conceptual level, which is perhaps not surprising since Stone is the prime architect of the System of Social and Demographic Statistics as well as the SNA. ${ }^{20}$ This facility is illustrated with respect to income distribution by the case studies discussed in the next section. In other areas, such as housing, calories, education and wealth, we have no empirical results as yet. But much a priori thought has been given to the issues, and a preliminary report is available. ${ }^{21}$ Essentially our view is that the integration must go ahead if the data system is to serve the policy debates which now widely maintain on these questions. Sen $(1973)^{22}$ has made reference to the problems for economists of abandoning the welfare principles of Pareto, and incorporating income distribution questions into their thinking. But there is no intellectual problem of integrating the income distribution component of the System of Social and Demographic Statistics into the SNA. Our experience is that the SAM framework is an invaluable aid in solving the empirical problems of doing so. It is also our experience that the end product is widely perceived to be relevant in a way that the standard SNA is not. Indeed our Swaziland case study derives directly from interest among individuals in the UK Overseas Development Ministry in the replicability of the study in Sri Lanka.

\section{IRAN CaSf: Study}

The case study of Iran resulted in the smallest and most confused of the SAM's presented here-some learning-by-doing has been involved through successive studies. The basic framework of accounts and estimates for 1970 are given in Table 1 which is extracted from the original source. ${ }^{2.3}$ It will be seen that the table resembles a conventional input-output transactions matrix since the first 12 rows and columns relate to the incomings and outgoings of a set of production activities. However, the remaining rows and columns record receipts and expenditures for other ascounts in the system (à la SNA) showing interrelationships between domestic and foreign institutions and not just the relationships between these institutions and production activities.

In the usual way, the first 12 columns show the outgoings of 12 domestic activities. These are made up of raw material purchases, payments to institutions of value added, imports of raw materials, and indirect taxes on inputs. The revenue of production ectivities derives from the intermediate sale of commodities, plus institutions' current expen.diture, exports, and sales of capital goods. Four institutions are cistinguished; three types of household; and the government. Value added is shown as a direct accrual to these institutions, so that company profit is already included as distributed income to households and government. This feature is important for comparison with the other case

\footnotetext{
${ }^{20}$ Stone's early thoughts on what cremtually became the SSDS were presented as the Radcliffe lectures at Warwick Iniversity in 1973.

${ }^{2}$ Pyatt and Thorbecke (1976). More detailed arguments are to be presented in Pyatt and Thorberke (forth:omıng). Meanwhile the issues are also addressed in United Nations (1977) as previously noted.

22 Based on the Radcliffe lectures, 1972.

${ }^{2.3}$ Pyatt et al. (1972). This paper is Technical Appendix 12 to the report of the WEP Mission to Iran. See International Labour Office (1973a).
} 
studies. Apart from value added payments arising out of production actirities, incomes are also created by households in furchasing domestic services, and by government through wage and salary payments for public administration. Gross national product at market prices $\left(771.2\right.$ billion rials ${ }^{24}$ ) comprises these elements of value added, together with net income $1 .$. : n abroad, and inclusive of indirect taxes; and this is shown in column 26 , distributed over the four institutions, as total incomings to their current accounts. Outgoings from the e accounts are shown in columns 14 through to 17 . They show expenditures of the institutions on domestic commodity outputs and on imports, besides payments of indirect and direct taxes. ${ }^{25}$ Since company profits are recorded as an ultimate receipt by households and government, no separate company accounts are shown. Therefore households and government are deemed to make investment expenditures on behalf of the companies which they own.

A feature of this framework is the distinction that is drawn between three categories of households. Rural households consist of all people in the rural areas, which in turn are defined in the censuses of population as places of under 5,000 inhabitants. The urban population is divided into two groups so that those households which fall in the top 30 percent of the urban expenditure distribution are classified as Urban II, and the remainder as Urban I. In other respects the SAM is fairly aggregative; for instance, only 12 production sectors are distinguished. However, the production sectors are chosen on a wider set of criteria than simply homogeneity or similarity of their product. The level of technology (modern versus traditional manufacturing) and ownership (resident cersus nonresident oil sectors) are also taken into account. ${ }^{26}$

The payment of factor income directly into institution accounts raised several difficulties. While data on aggregate value added, by activity, were available from published sources, the allocation of these sums direct to the three household types and to government had to be more subjectively estimated within constraints set by the classifications themselves, e.g. rural wages must accrue predominantly to rural households; and by controls on total incomes from all sources, which were known or could be estimated.

On the expenditure side of the institution accounts, separate commodity expenditures are shown for the three types of household and for the government. The allocation of private consumption between Rural, Urban I and Urban II households was made on the basis of a Family Budget Survey for 1965 carried out by the Central Bank. An important point to note is that, after allowing for indirect and direct taxes, and for imports, the difference between houschold expenditures and gross household incomes yields household savings. Government savings are similarly derived.

The capital accounts are highly aggregative. The three houschold accounts are consolidated, so that the three savings figures are shown as incomings to a

\footnotetext{
${ }^{24}$ Shown in cell $(18,26)$.

${ }^{25}$ For the government direct taxes are a negatise outgoing (a receipt of taxes from households) since it is a transfer between instituitions.

${ }^{26}$ The non-resident oil sector is excluded from the production activities distinguished in the table. Its contribution to national product is treated as an indirect tax receipt on exports, i.e., in row 20 , column 19.
} 
single capital account. Flow of funds, shown in the three penultimate rows and columns of the SAM (23 to 25) is, in consequence, of a very simple structure. The balance of payments deficit 1.36 .0 billion rials in 1970$)$ is financed by capital transfers to housholds ( 16.7 hillion rials) and to government ( 19.3 billion rials). Domestic savings are supplemenicd hy these capital transfers from abroad to finance domestic insestment. The financing of the private and public components of domestic vestment is facilitaled by a capital transfer from households to government of 41.6 billion rials.

The resulting SAM for Iran is of a very simple design. Iowever, it is worth noting that it was produced in a matter of days, rather than weeks, by two people on the basis of (i) considerable re: rant knowledge of a generalized kind; (ii) using published sources almost entirely; and (iii) working in association with others. ${ }^{27}$ In the event, the feasibility of the exercise depended crucially on the rigors imposed by the accounting constraints in a SAM. since only in this way could the better data be fully exploited to support the weuher and more doubtrul figures. Of course, had better data been available, it would have been used. In this sense Table 1 presents the best that could be obtained for Iran in 1970) without new primary information. Its quality owes much to the discipline of working in a SAM context and, it was judged, was adequate to support a modelling exercise for Iran which comsickerel the two-way links between production structure and income distribution referred to varlier. Aspects of the model used in conjunction with Table 1 and some of its analytic propertices have been discussed elsewhere, as well as in the original source." These need not concern us here beyond noting that the "single entry" accomnting which characterizes a SAM requires that licitment of items as a receipt must be comsistent with their treatment as an expenditure. In a model context this means that the effects of income distribution on production must be consistent with the effects of production on income distribution if the results of the model are to be expressed as a new SAM in the format of Table 1.

\section{SRI LANKA CASI: STHIJY}

The experience of the Iran study indicated that data requirements, not modelling, were the main ubstacle to progress with planning techniques which embrace employment and distribution questions. Accordingly our subsequent efforts have focused in this direction. ${ }^{29}$

\footnotetext{
${ }^{2 \%}$ The prime calibrators of the Iran matrix were Julian Bharier and Robert Mabro. Other members of the team were Rohert Lindley, (iraham Pyatt and Yves Sabolo. The team report (Pyatt et al. (1972) discusses sources and methods in detail. That such an approach was worth trying emerged from a preliminary reconnaissance of the issues with Abdul Menuil, who had previously constructed a more conventional input-output model which was not available to us.

${ }^{28}$ See ('hapter 5 of Blitzer, (lark and Taylor (1975) More on the properties of the model is included in Pyatt and Thorbecke diorthommg)

${ }^{29}$ This is not to say that modelling questuons have been ignored. See, for example, Pyatt and Thorbecke (forthoming). These subsequent effort hive all been supported by research funds: in the Sri Lanka case from WEP Research as part of the follow-up prugramime on problems to emerge from its other activities. At the same time, Government support in the country under study was vital in both Sri Lanka and Swaziland.
} 
TABLE 1

THE SOCIAL ACCOUNTS OF IRAN 1970 (BILLION RIALS)

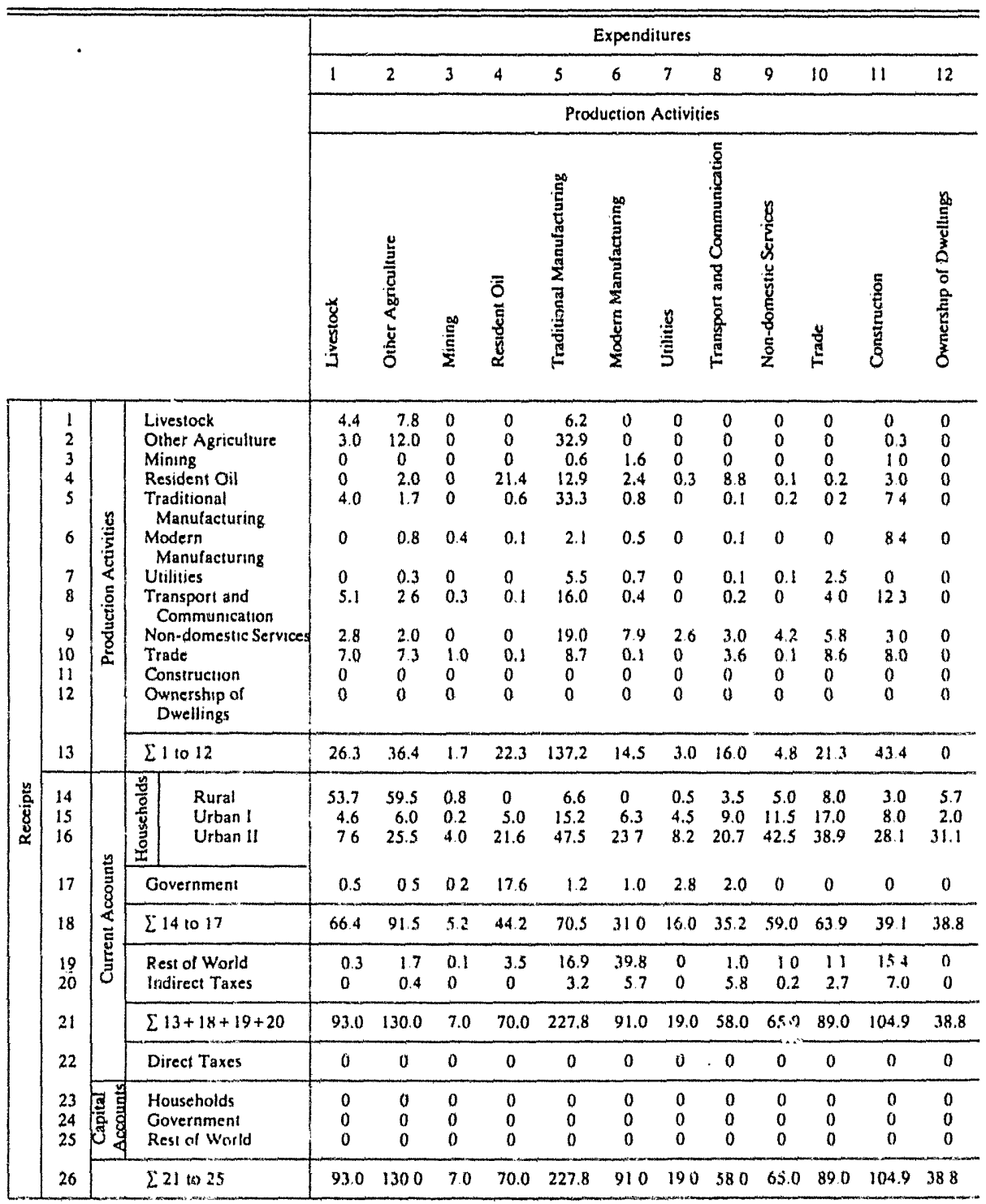




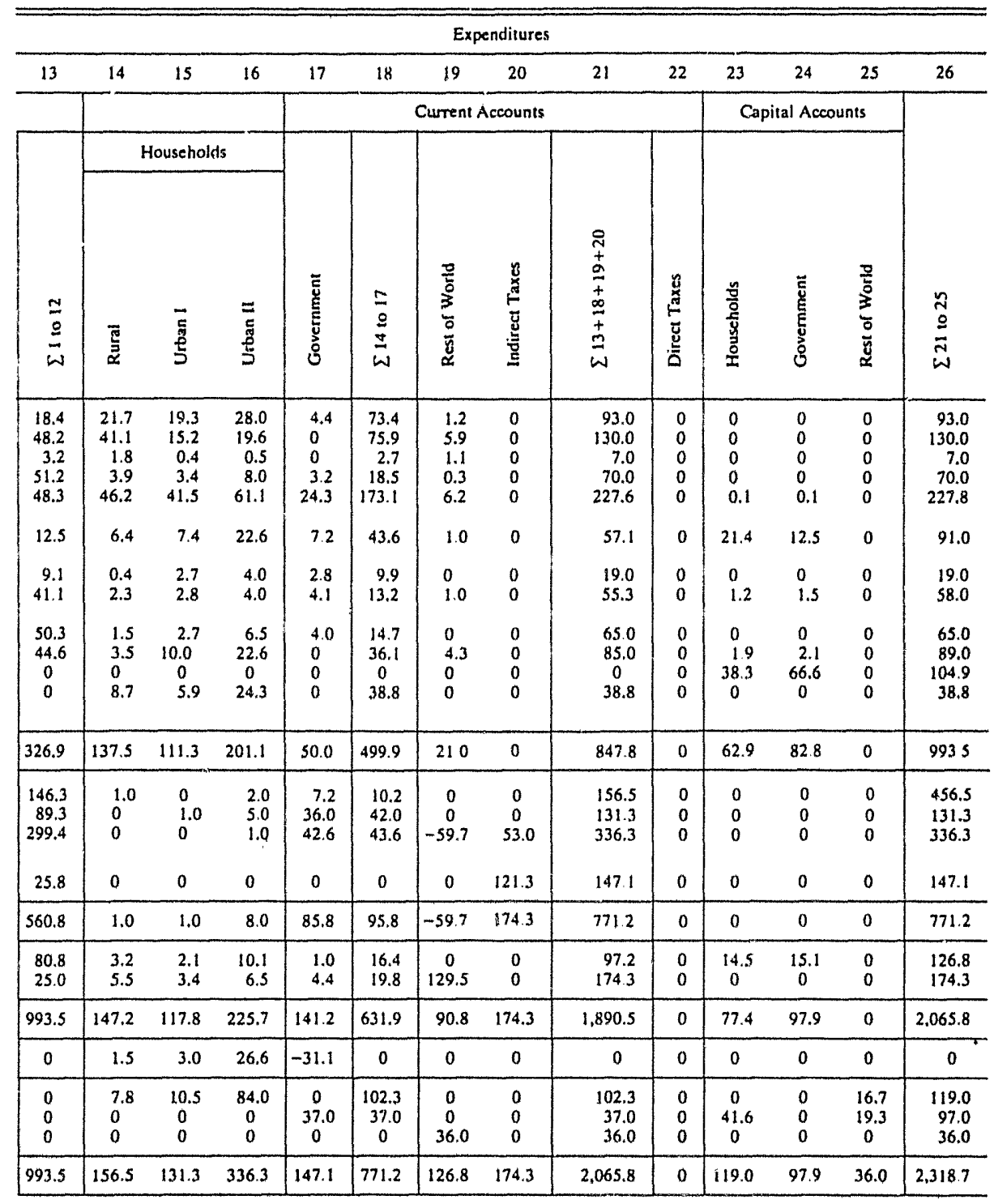


The SAM for Sri Lanka shown in Table 2 indicates some of the innovations that were achieved in this study. Two of these are as follows. First, it is immediately apparent that $t$ : ere is a new set of accounts, not included in the Iran matrix, relating to the factors of production. And secondly, the accounts have been rearranged, so that, for example, the factor accounts lead in the rows and columns. A third difference, not readily apparent from the table, relates to the compilation of the accounts. Each of these will be discusseci $n$ turn in this section. But first it needs to be emphasized that the slucly in Sri Lanka was a much larger exercise than that in Iran so that Table 2 is only a sumnary of results for the latter, while Table 1 is more nearly exhaustive of the output of the Iran study. ${ }^{30}$ This difference in order of magnitude is discussed later. Meanwhile, some further comment on each of the three points previously referred $t o$ is in order.

The factor accounts in Table 2 are additional to the production and institution accounts shown hitherto. Their main purpose is simply stated: it is to receive factor payments, both from domestic production activities and from the rest of the world. These in turn are mapped into the household and other institution accounts, thereby recording the factor income component of the gross income receipts of institutions. Non-factor incomes, such as current transfers between institutions and transfers from the rest of the world, augment factor incomes to yield gross incomes of institutions.

The distinclion between factor and institutions accounts serves two important purposes. In the first place, a clear distinction can be made between factor income and non-factor income that arises from the redistributive process within the economy. These redistributive forces are likely to be a centurpice of policy and planning strategy, and therefore need to be captured in this way. In the second place, the classification of factors can be entirely divorced from institutional classifications. The latter can be ietermined by a range of socio-economic considerations; for households these may include location and socio-ethnic factors as well as income level; for other institutions "ownership" or "purpose" might be appropriate. The Sri Lankan institutions shown in Table 2 are in fact an aggregation of more detailed accounts. Thus in the full study each of the three household classes are further subdivided by six income groups; and the government accounts are disaggregated into ten categories for income receipts, and nineteen heads (or accounts) for expenditure. Similarly, in the full study, the classification of factors is according to the kinds of economic agents that are employec by production activities and thereby receive factor returns. In Table 2 only six factors are shown, but this is a more aggregated version of the classification which was in fact utilized. For example, threc kinds of labour are distinguished in Table 2 (urban, rural and estate labour) athough a disaggregation of labour income by nine occupational groups was also achieved. Three ron-labour factor acc 'ints are distinguished: the factor "housing" simply receives imputed rents on owner-oceupied housing, whilst all other returns are divided between private and public ownership of capital. Each of the six factor accounts has a row sum which accumulates all domestically generated factor

${ }^{30}$ The Iran study additionally involved an estimated SAM for 1972 and detailed analysis of labour statistics as well as the modelling work previously referred to. 
incomes, together with net factor income from abroad which is shown to accrue to the factor "other private capital". The total of all factoral row sums conveniently shows GNI at factor cost (Rs. 11360 millions in 1970), while the arrangement of the table puts the individual factor accounts first so that the decomposition of GNI into its factoral distribution is also given prominence.

The arrangement of accounts in the table is a conscious attempt to capture the circular flow of income-from income generated by activities to factors; from factors to the institutions that provide factor services; and from the expenditure of income by institutions to demand on activities, and hence income generation. It is also an attempt to give prominence within SAM to the things that matter most. For us these are employment and income distribution questions, set in a framework of the level and structure of activity. Thus our accounts start with factor incomes and move next to the incomes of households and other institutions in the economy. These are our primary concerns, not the structure of production.

A third innovation in our Sri Lanka study concerns the practical procedures for compilation of the SAM. In many ways the data base for Sri Lanka differed from the situation encountered for Iran, although the basic notion that the SAM imposes a discipline for data consistency was sustained. Some details of the methods used to construct the Sri Lanka SAM may be of particular interest since these involved several features that we believe are quite novel with respect to social accounting for developing countries. ${ }^{31}$

In close correspondence with SNA guidelines our Sri Lanka SAM is built up from data on the supply and disposition of commodities, traced through the rows and colurnns of the production accounts. Using a 1965 input-output matrix to depict the approximate structure of production, the commodity balances for Sri Lanka in 1970 were achieved in a systematic, although non-trivial, way. The complicating factors were not only incomplete or uncertain data, but also multiple estimates of some elements. Thus, for example, we were faced with two (or more) estimates of most value akded components, " while available figures of gross outputs were recognized to be subject to a substantial degree of error. However, for the most part the final use components of commodity requirements (household and government expenditure, fixed capital formation and exports) were more reliablc. The main exception is the vector of changes in commodity stocks, and this was used as a residual in the commodity balance calculation.

The derivation of a set of commodity balances was achieved in four stages. The first set of commodities that were considered were those which make no sales on intermediate account whatsocver: in Sri Lanka these sectors were tea, bread, other bakery products and tobacco manufacturing. These were the first to be investigated since final sales must also be equal to gross sales and gross output for these sectors. On the input side, with gross outputs now ascertained, the input technology (determined principally by the $1965 \mathrm{I}-\mathrm{O}$ matrix) gives some value added estimates as well as cstimates of intermediate input requirements

\footnotetext{
${ }^{31}$ The most recent national accounts for Malaysia make use of the same approach as is described below. See Malaysia, Department of Statistics (1976).

${ }^{32}$ One from Ceylon, Census and Statistics (1973), the other from (eylon, Central Bank (1971).
} 
for these sectors. Alongside these four sectors were some that were known to have few sectors to which intermediate sales were made; rubber and fishing, for example. The second group of sectors to be investigated were those belonging to what we term "process loops". The coconut group is one such example. There is a linkage between the three sectors: coconui; dessicated coconut and copra; and coconut fibre and yarn. For these sectors intermediate sales and purchases do exist but they are largely confined within the process loop. ": is infermedialle sales can easily be estimated from the final demand estimates, given some knowledge of the nature of the interaction between the variuss sectors within a loop. For example, the gross output of the sector coconut fibre and yarn can be set equal to its final demand entry since it has almost no intermediate sales. Working through the backward linkages in the loop it was possible to iterate (1) feasible (though admittedly, not unique) solutions for the gross output, value added and intermediate transactions of each of the sectors involved. ${ }^{33}$

The third stage of the commodity balance procedure was to investigate the remaining sectors. Clearly some intermediate sales had been determined from the first two stages and this limited the problem. Knowledge of these allowed sectors to be ordered so as to first consider those that had relatively few undetermined intermediate transactions. The fourth and final stage was to review the feasibility of the initial estimates of value added, gross outputs and intermediate transactions. Inevitably this stage revealed some anomalies and it proved necessary to repeat the first three stages, in an itcrative manner, eventually converging to an overall feasible matrix that was not unaccepliahle on the basis of the facts. ${ }^{34}$

The balanced production accounts determined a consistent set of value added estimates for the forty-eight production activities in the study. 'The way in which they were derived took full cognizance of the various prior cistinutces of value added. Changes were made even to the firmest of these estirnates if there occurred even firmer estimates of commodily supplies and dispositions which were inconsistent with the value added data. This implies, and it is perhaps worth noting, that our experience is at variance with the contention that estimates and "guesstimates" should not be placed side by side. ${ }^{35}$ The SAM consistency framework forces a confrontation between various data sources which can never be reasonably expected to be of equal quality. Reconciliation of data of varying qualities is therefore unavoidable. Moreover, unless data are literally useless they can add something to SAM calibration. There is no sensible alternative therefore to setting all sources (with prior judgment regarding their relative reliability) alongside one another and executing an "optimum" halance. (Onc

\footnotetext{
${ }^{33}$ Sectors belonging to a process loop form a natural agglegale sectol, of course, hut it in convenient on occasions to distinguish between them, as when, for eximple, the outputs wrve different export markets as well as further stages in the product process.

${ }^{14}$ In his foreword to Pyatt and Roe with Lindley, Round and ollers (fortheoming). Stone hath suggested that more formal techniques of data recomcilimm may have advantages. He refers in particular to statistical techniques that iteratively balance the accounts suliect to initial estimates and sets of constraints, both of which may be suljece to uncertainty. Pursuit of this issue is the subject of continuing research in the Development Rescarch ('enter. World Bank. Some initial results are given in Byron (forthcoming).

${ }^{35}$ See Barkay (1975) for a statement of this view.
} 
conseguence of doing so is that the $\$ A M$ approwh leathes a great deal about statistical priorities for neve: informution.

After the production account', the next step was to obtain a balance of all the institution and factor accoints. From several tandpoints the government

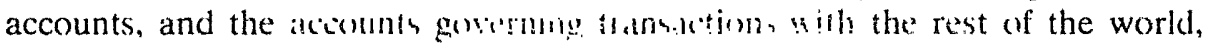
were the firmest. They theretore lonmed a basis for this part of the matrix. However, we were particularly fortunate in being able to utilize a Socio-

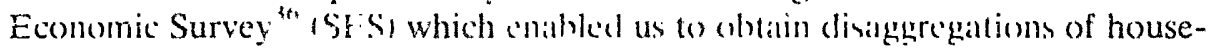
hold expenditures according to urban, rural, and estale subáivisions. Not surprisingly, SES cstimetes of houschold (and factor) incomes implied negative savings in all houschold grump, confirming a priori expectations of underrecording of incones in hounchold surveys. In this situation, assumptions about the economy-wide capital/ investment and retained profits. and the implicit constraints of the SAM, were all utilized to obtain a feasible solution to the remainng cell entries, including revised estimates of hourchold incomes and savings.

The complete table has 87 rows and 96 columns as shown in Table 3 which gives listings of the detailed accounts in the full study. Justification for these and the full results are set out in Pyit and Roe with $I$ indley, Round and others (forthooming) which atlempls to record the manyear of work which went into the study. ${ }^{37}$ However, it can be noted that this manyear was in fact collapsed into a period of less than three months, with the team insoled averaging some six people through this period. ${ }^{\text {is }}$

There are two further comments to be made on the Sri I anki study. The first is that it will be recalled that the purpose of the exercise was not to build a model as such, but rather to push forward the possibilities for modelling by resolving some of the problem of diatia system design and availability. Accordingly we have not built a Sri I ank.l model as such. However, Pyatt and Roe with Lindley, Round and othes Iforthoming) includes a number of empirical exercises using the data and homing its immediate relevance for policy issues. These cxcrcises include a description of the commmy with reference to income distribution: the output, income and employment multipliers in the economy; an analysis of export incentives and of effective protection: and a study of the structure of husehold cxpenditure in Sri Lanka which focuses on its sensitivity to the income distribution. These, then, are some of the products which can be obtained short of a full scale model once data has been set up consistently in a SAM framework.

\footnotetext{
"See ('eylon. Department of (ensus and Statistles $(1)^{7} \mid 1$.

"The $87 \times 96$ matrix was estimated in full detail subject to one eaveat. "This arises because estimates of current transfers between instututum eould not be ohtained at the level of detail of Table 3, but only at the more agncfille letel of lable 2. (3theruine the $87 \times 96$ matrix was estimated in full. Thus at the full level of detal only the 18 household current accounts are incomplete, but fuil

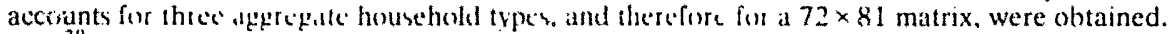

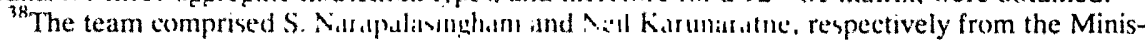
try of Plamme and F mplownem and the Industral Development Board, Sri Lanka; Alan Brown and Robere Mabro from ()xford Innersity, and Robert lindley and Alan Roe, in addition to ourselves, from the I Iniversity of Waruick.
} 
TABLE 2

A SOCIAL ACCOUNTINo MATRIX FOR SRI LANKA, 1970

(MILLIONS OF RUPEES)

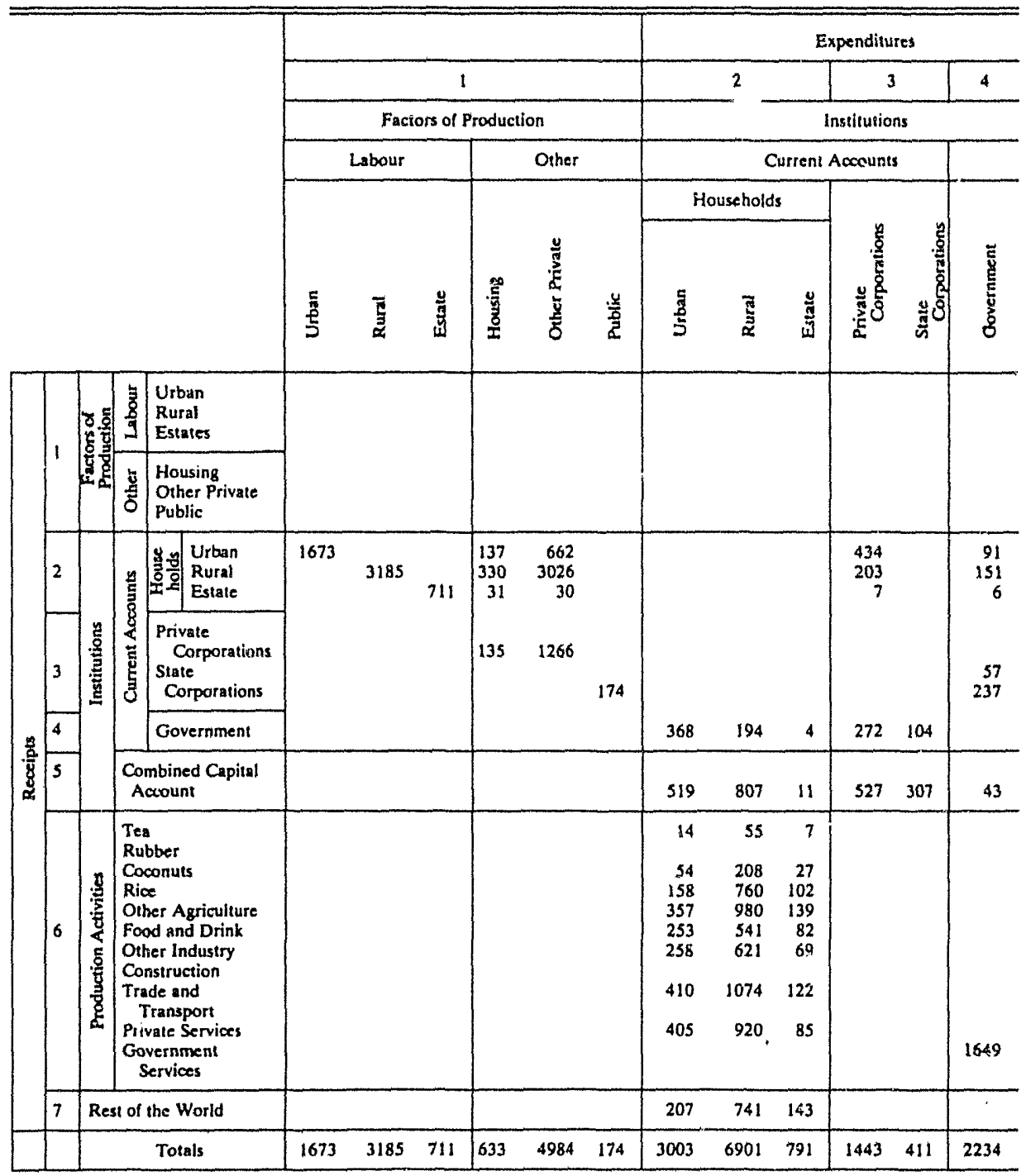




\begin{tabular}{|c|c|c|c|c|c|c|c|c|c|c|c|c|c|}
\hline \multirow[b]{2}{*}{5} & \multicolumn{12}{|c|}{ Expenditures } & \\
\hline & & & & & & 6 & & & & & & 7 & \\
\hline \multirow{3}{*}{ 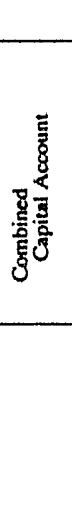 } & \multicolumn{11}{|c|}{ Production Activities } & \multirow[b]{2}{*}{ 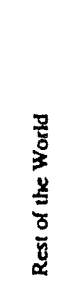 } & \multirow[b]{2}{*}{ है } \\
\hline & ఝే & 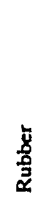 & 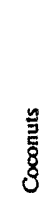 & 8 & 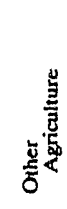 & 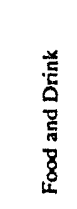 & $\begin{array}{l}\frac{D}{5} \\
\frac{3}{E} \\
\frac{5}{5} \\
\frac{5}{0}\end{array}$ & 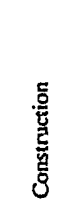 & 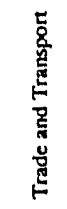 & 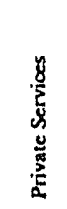 & 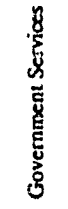 & & \\
\hline & $\begin{array}{r}5 \\
43 \\
526 \\
\\
13\end{array}$ & $\begin{array}{r}5 \\
153 \\
133 \\
\\
24\end{array}$ & $\begin{array}{r}9 \\
67 \\
11 \\
\\
442\end{array}$ & $\begin{array}{r}25 \\
706 \\
\\
282\end{array}$ & $\begin{array}{r}75 \\
247 \\
5 \\
\\
1259 \\
-11\end{array}$ & $\begin{array}{r}46 \\
68 \\
4 \\
\\
184 \\
12\end{array}$ & $\begin{array}{r}182 \\
259 \\
2 \\
\\
604 \\
109\end{array}$ & $\begin{array}{r}81 \\
159 \\
5 \\
\\
742 \\
-8\end{array}$ & $\begin{array}{r}414 \\
487 \\
8 \\
\\
1424 \\
-1\end{array}$ & $\begin{array}{r}276 \\
276 \\
12 \\
\\
633 \\
123 \\
73\end{array}$ & $\begin{array}{r}555 \\
715 \\
5\end{array}$ & -113 & $\begin{array}{r}1673 \\
3185 \\
711 \\
\\
633 \\
4984 \\
174\end{array}$ \\
\hline 313 & 33 & 4 & 14 & 10 & 19 & 288 & 216 & 66 & 130 & 76 & 29 & $\begin{array}{r}6 \\
6 \\
6 \\
-15 \\
\\
94\end{array}$ & $\begin{array}{r}3003 \\
6901 \\
791 \\
\\
1443 \\
411 \\
2234\end{array}$ \\
\hline$\gamma$ & f & & & & & & & & & & & 425 & 2639 \\
\hline $\begin{array}{r}-55 \\
25 \\
29 \\
105 \\
\\
37 \\
72 \\
1595 \\
154\end{array}$ & $\begin{array}{l}11 \\
97 \\
50 \\
11\end{array}$ & $\begin{array}{r}1 \\
24 \\
10 \\
3 \\
.\end{array}$ & $\begin{array}{l}9 \\
8 \\
7\end{array}$ & $\begin{array}{r}1082 \\
2 \\
9 \\
35 \\
\\
44 \\
15\end{array}$ & $\begin{array}{r}95 \\
11 \\
69 \\
23 \\
1\end{array}$ & $\begin{array}{r}239 \\
\\
63 \\
24 \\
49 \\
+\quad 95\end{array}$ & $\begin{array}{r}8 \\
8 \\
2 \\
34 \\
188 \\
554 \\
1 \\
249 \\
4\end{array}$ & $\begin{array}{r}3 \\
417 \\
206 \\
9\end{array}$ & $\begin{array}{r}172 \\
7 \\
96 \\
38\end{array}$ & $\begin{array}{r}2 \\
\\
6 \\
15 \\
39 \\
29 \\
37 \\
50 \\
42 \\
55\end{array}$ & $\begin{array}{r}2 \\
\\
4 \\
18 \\
16 \\
8 \\
66 \\
92 \\
59 \\
37\end{array}$ & $\begin{array}{r}839 \\
341 \\
2 \\
\\
106 \\
94 \\
241 \\
\\
203 \\
287\end{array}$ & $\begin{array}{r}864 \\
374 \\
577 \\
2242 \\
1846 \\
1276 \\
2790 \\
1745 \\
2845 \\
1877 \\
\\
1649\end{array}$ \\
\hline 364 & 75 & 12 & 10 & 32 & 53 & 204 & 370 & 65 & 70 & 133 & 43 & & 2522 \\
\hline 2639 & 864 & 374 & 577 & 2242 & 1846 & 1276 & 2790 & 1745 & 2845 & 1877 & 1649 & 2522 & \\
\hline
\end{tabular}

Note: This is a preliminary version of a table to appear in Pyatt and Roe with Lindley, Round and others (forthcoming). 
The second and final comment on Sri Lanka is that increasingly, as countries come to adopt the SNA (and hence the commodity balance approach), the above discussion of the way in which we were able to implement it may be of interest. However, the methods which proved successful in Sri Lanka were challenged by the subsequent study of Swaziland. Comment on these methods is reserved, therefore, until after the description of our work in Swaziland.

TABLF 3

SUMMARY OF' THE EXTFNT OF DISACIURR-(IAIION OF THE FUILL. SRI LANKA SAM

\begin{tabular}{|c|c|c|}
\hline $\begin{array}{c}\text { Aggregate Accounts as in } \\
\text { Table } 2\end{array}$ & $\begin{array}{l}\text { Number and Nature of } \\
\text { Component Accounts Shown } \\
\text { in the Rows }\end{array}$ & $\begin{array}{l}\text { Number and Nature of } \\
\text { Component Accounts Shown } \\
\text { in the Columns }\end{array}$ \\
\hline (1) Factors of Production & $\begin{array}{l}\text { (three accounts for } \\
\text { different employment } \\
\text { statuses and three } \\
\text { accounts for the factor of } \\
\text { production, capital)* }\end{array}$ & 6 \\
\hline (2) Firms & $\begin{array}{l}3 \text { (Prisate, Public Financial } \\
\text { Institution, Other Public } \\
\text { Companies) }\end{array}$ & 3 \\
\hline (3) Households Current & $\begin{array}{l}18 \text { (Urban. Rural and } \\
\text { Estate and within each of } \\
\text { these, six income classes) }\end{array}$ & 18 \\
\hline (4) Government current & $\begin{array}{l}\text { 10) (seven categories of } \\
\text { tax, one account for } \\
\text { current transfers, one } \\
\text { account for Local } \\
\text { (ioreinment and a } \\
\text { summary account) }\end{array}$ & $\begin{array}{l}19 \text { (eight accounts for } \\
\text { crpenditure on goods and } \\
\text { services, nine accounts for } \\
\text { transfer payments, one } \\
\text { account for Local } \\
\text { Government and one } \\
\text { summary account) }\end{array}$ \\
\hline $\begin{array}{l}\text { (5) Consolidated Capital } \\
\text { Account }\end{array}$ & 1 & 1 \\
\hline (6) P:oduction Activities & 48 & 48 \\
\hline (7) Rest of World-Current & 1 & 1 \\
\hline Total & 87 & 96 \\
\hline
\end{tabular}
capital.

*We have also produced alternative factor accounts showing nine categories of skill as well as

\section{SWazil AND CaSf STUDY}

Interest in the replicability of the Sri Lanka case study led to a group of similar size spending six weeks in Swaziland and about the same time subsequently in an attempt to set the major economic statistics in a SAM context. ${ }^{39}$

${ }^{39}$ The group was financed by the $\mathrm{ESCOR}$ committee of the Overseas Development Ministry (ODM), London. It comprised Harry Fell and Stanley Webster. on secondment from the ODM; Graham Jones and Maicolm Wialmvley from the Department of Statistics, Ministry of Finance and Planning, Mbabane: and the same four Warwick colleagues as on the Sri Lanka study, plus Paul Stoneman. 
As in the Sri lanka case, there was no initial intention of undertaking modelling work immedialcly, and the focus was an colleivour to contribute directly to policy discussion on the basis of an understanding of the conomy for which the SAM exercise was to be the catalyst.

In several respects Swaziland offered the opposite to Sri Lanka in terms of available data. Not least the SAM framework which we intended to estimate, and which was bread! 'omparable with the Sri Lanka matrix in its dimensions, was not fully determined by available data. This was a marked contrast to the Sri Lanka SAM which had been overdetermined as a result of the multiplicity of sources and estimates. Whilst the details of achieving SAM estimates differed markedly between Sri Lanka and Swaziland, it is interesting to note that a common basic approach was sustained, and the discipline underlying the SAM was revealed to be of unquestionable value in deriving estimates.

Table 4 sets out iggrequle accounts for Swaziland for the year 1971-72. These are aggregative in the sense that more detailed estimates were obtained corresponding to disaggregations of some of the accounts shown. Thus although the 9 factor accounts and 17 institution accounts of the study are shown in full detail, Table 4 consolidates into one account each the 44 commodity and 25 production activity accounts which were distinguished. The distinction of activity accounts from accounts for the commodities which they produce comprises one of the main differences between the Swaziland and Sri lanka matrices. This is, of course, very much in line with the SNA guidelines and we found that the distinction afforded a conceptual flexibility in the definition of activities and commodities which was also advantageous in the estimation of the matrix clements. Before considering the commodity/activity distinction and the determination of the commodity balances for Swaziland, there are several classifications embodied within the factor and institution accounts that require further discussion.

The nine factor accounts, distinguished in the first nine rows and columns of the matrix that comprise Table 4 , are novel in several respects. It should first be understood that the organizational aspects of the supply of agricultural factor services within Swaziland are complex: part of the land is held by the Swazi Nation and the remainder is still owned by individuals-often non-Swazis-and is generally farmed according to modern agricultural technology. Within the Swazi Nation I and, Rural Development Area (RDA) schemes are currently being introduced and represent a significant break from traditional methods. ${ }^{40}$ In order to avoid an arhitrary division of the returns to land and labour of the self-employed in the agricultural sector, a composite factor was defined for each of these three types of land: Swazi Nation (traditional), Swazi Nation (R.D.A.) and Individual Tenure Farms (I.T.F.), Labour receiving employee compensation is shown as a separate category, as is self-empluyment income from nonagricultural activities. It is also worth noting that in the Swazi context the same individual may be supplying his services in the form of two factors in the course of a normal year. For example, he may be working on the rural homestead, and thus accruing factor income of the first kind, and also receiving employee

${ }^{411}$ For 1971.72 this distinction within Swazi Nation Land is not of great significance, but for monitorng progress within the R.D.A.'s it is ultimately a distinction of considerable policy interest. 
TABLE 4

The Social accounts of SWaziland 1971-72 (MILlion Emalangani)

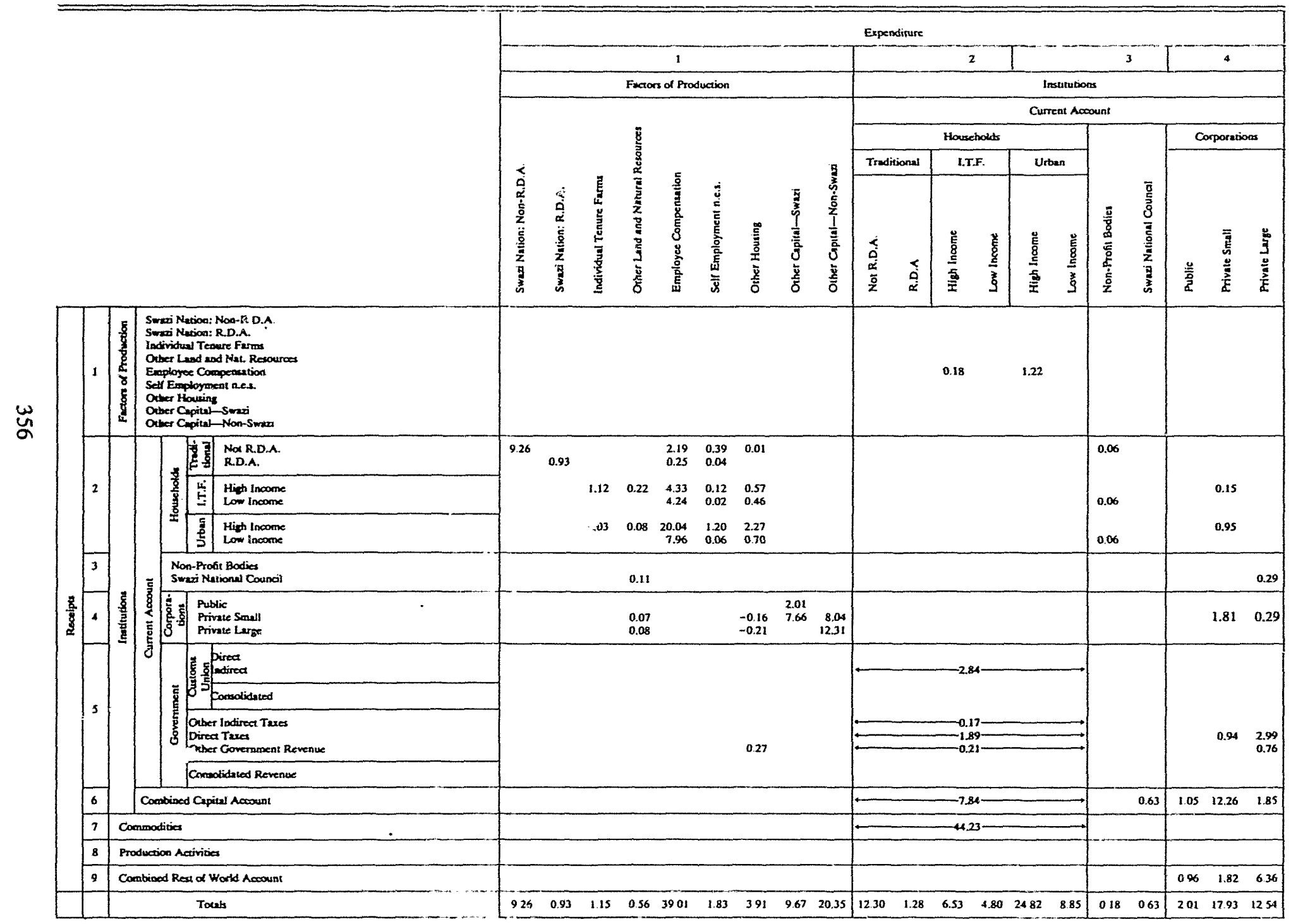




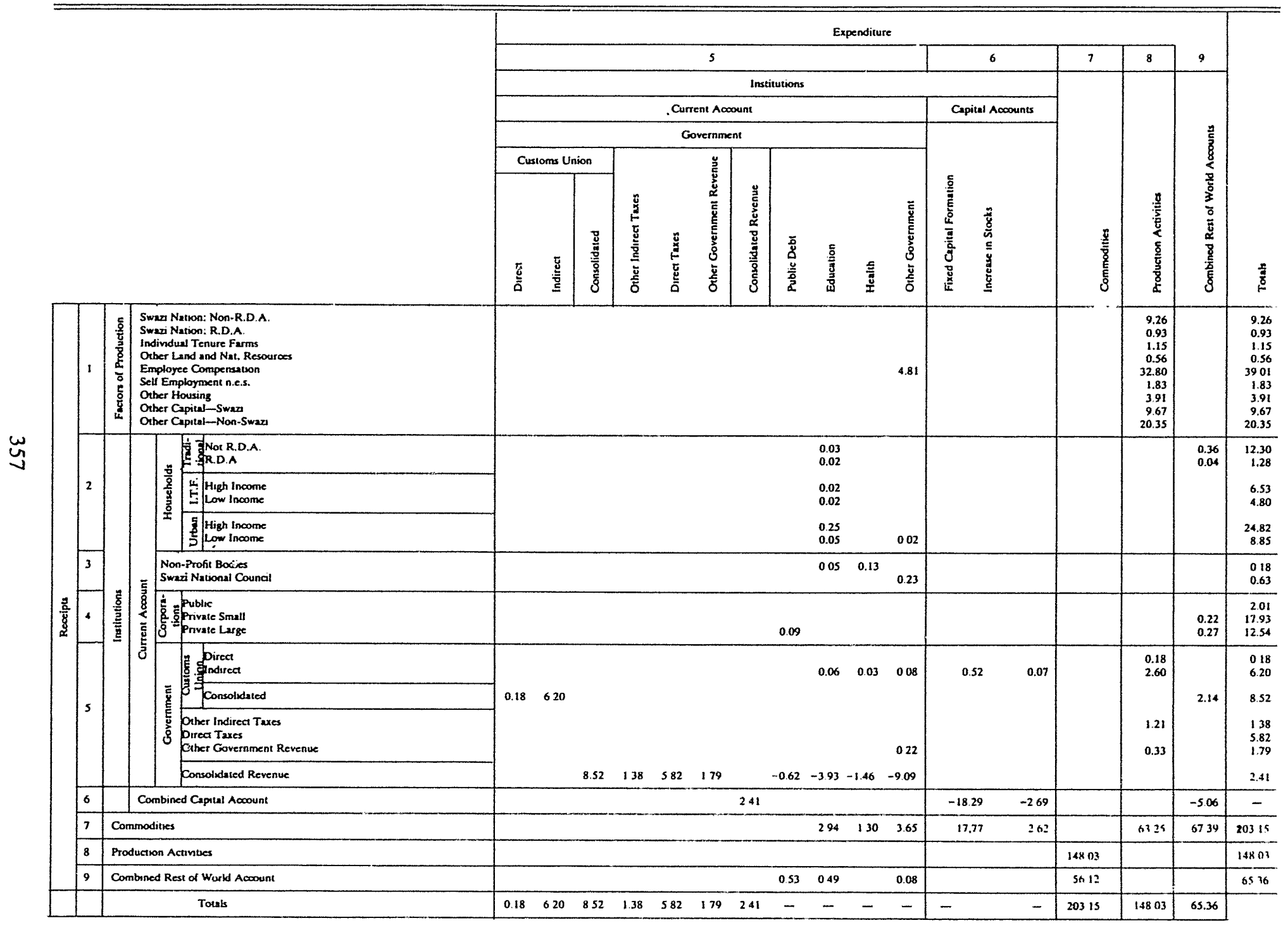


compensation for casual work in urban areas. More typical, however, is the instance where members of a rural homestead (household) will be supplying a variety of factor services in both rural and urban districts. In such situations the importance of distinguishing ractors from institutions, and of carefully defining classifications for each of them, is obvious. Finally, returns to "other capital" (i.e. capital other than land) are distinguished as between Swazi and non-Swazi controlled, a distinction which is of considerable importance in the policy context.

The first two institution accounts relate to two forms of traditional Swazi household: those outside and those within the Rural Development Areas. Each household receives the major part of its gross income from the factor income deriving from its traditional agricultural activity, although typically this is supplemented by employee compensation and self-employment incomes. The main sources of the supplementation are employment on the Swazi Nation Land, in Small Traders' establishments and in rural education and health services. ${ }^{41}$ Households on Individual Tenure Farms and in urban areas are further subdivided into high and low income groups according to whether their aggregate income is greater or less than $\mathrm{E} 600^{42}$ per annum. The remaining institutions are non-household institutions. We attributed separate categories to Non-Profit Bodies (which receive transfer income from government expenditures on health and education), and the Swazi National (ouncil (which essentially receives income in the form of rent and mineral royalties). Three corporate categories were distinguished, which allowed separate accounts for large and small corporations.

The merit of the distinction within a SAM between factors and institutions is more clearly seen in Swaziland than in our other studies. At the same time flexibility is important since the distinction is most informative (and useful for modelling applications) when the classifications are chosen to reflect the particular structure and organization of each country. Accordingly we are against stereotypes for the detailed classifications. The classifications appropriate to the Swazi economy are only approximately replicated in other developing countries. In particular the "Swazi Nation" is a unique organizational form, and whilst it is important to reflect this aspect in the national accounting system for Swaziland, there may be no analogue for other countries.

The data base was constructed from a variety of detailed sources. The national accounts statistics were a crucial input but, unlike the Sri Lanka situation, there were relatively few occasions where multiple estimates were available for the major elements. However, for the most part value added payments by production activities (in aggregate) were readily obtained. An important exception to this concerns the distinction between RDA and non-RDA factors and houscholds. Simply the level of activity of RDA's was globally estimated to be 10 percent of other traditional agriculture and this percentage was applied

\footnotetext{
${ }^{41}$ Note that ieachers, for example, who are teaching in schools and living in Swazi Nation Land are included in this part of the rural sector.

${ }^{42} \mathrm{E}$ is the standard reference for the currency unit, the Fimalangani.

${ }^{43}$ The need for import data arose mainly because of the need to estimate Swaziland's revenue entitlement from the Southern African Customs Union.
} 
throughout the accounts in order to distinguish RDA and non-RDA classes. This was the most arbitrary of the assumptions made and would ha" 3 been avoided had it not been considered important to demonstrate how a SAM could be designed to monitor the future progress of the RDAs when independent data become available.

The derivation of the commodity balances differed substantially as between Swaziland and Sri Lanka in several aspects. However, these balances still proved to be a useful starting point for the framework, and probably provided some of the firmest estimates in the accounts as a whole. With no input-output table having been derived previously, it was necessary to construct matrices showing the intermediate requirements of commodities by activities (absorption matrix) and the domestic supply of commodities by activities (make matrix) from the available evidence. This included detailed statistics of the commodity inputs and outputs of manufacturing sectors, together with much detail on commodity imports. ${ }^{43}$ At the present stage of development Swaziland has a very simple commodity output mix, so the build-up of an absorption matrix took the form of commencing with the structure based upon imports, and then allocating the domestic supplies along its rows. The whole operation was tentative since total intermediate inputs, o stained by netting value added from gross outputs, provided a set of constraints. Since imports of consumer goods and capital goods were distinguishable, the only major problem was to identify the stock elements of each purchase. As in the Sri Lanka case study, the vector of increases in stocks tended to be derived as a residual of unallocable items.

The detailed procedure for allocating domestic supplies by both sector and use followed a similar theme to that of the Sri Lanka study. That is, many commodities could be readily identified as final use (usually export) oriented, or process-loop in nature. This considerably aided what otherwise might have been a formidable task. Our experience also showed that a high degree of commodity detail helped us to identify using sectors more easily.

Swaziland has not carried out a comparable household income-expenditure survey to that of Sri Lanka. In consequence it proved to be impossible to derive disaggregations of houshold expenditure on commodities beyond that of an overall urban/rural distinction, augmented by separate treatment of high income Individual Tenure Farmers. Even this was only possible by "borrowing" a set of expenditure coefficients from a rural household expenditure survey that was undertiken for nearby Lesotho. A further consequencc of this lacuna is that no detail could be ohtained on the savings propensities of the various household groups, although corporate savings and consolidated government savings were defined more explicitly.

Thus the Swaziland study serves not only to endorse the advantages of an approach which starts with commodity balances, but also to underline the importance of multi-purpose household surveys in seeking to obtain an integrated set of accounts. As it is the tablc was not completed. However, it is perhaps interesting to note that at least it was available before the national accounts for the same year.

A final point on Swaziland is that the data base has been used subsequently for some model work. This arose from the need to consider some specific 
investments which were non-marginal to the economy. Their evaluation took the form of a project appraisal based on a macroeconomic model. This was new ground which, experience suggests, was well prepared by the SAM approach. ${ }^{44}$

\section{CONCLUDINC; ComMENTS}

There are a number of issues which have arisen in the curse of our work yet are barely touched on in the preceding discussion. They are worth noting, however, in this concluding section, and suggest avenues for future work which may be of general interest. To give them perspective we can begin with a summary of the main points which the above discussion is intended to argue.

First the SAM approach has proved in our experience to be a practical working tool of considerable merit in making the best use of available data and in providing a quantitative basis for anlysis. It inevitably involves using data of variable qualities, and called for skills in data reconciliation which have not required the same emphasis in the past. It would undoubtedly be of value (and also a comfort) to have available formal techniques for pooling dati. These can be expected to be forthcoming in due course. ${ }^{45}$ Meanwhile the informal methods have to suffice and the exercise of reconciliation gives a focus to discussion of statistical priorities which is most valuable.

Secondly, the SNA recommendation that SAM's should be approached through commodity balances has served us well: and the refinement of having separate commodity and activity accounts is valuable both for implementation of a SAM and as an aspect of subsequent modelling.

Next, we have concluded not only that it is possible to disaggregate the household sector, and hence to build income distribution into the macroeconomic picture, but also that it is desirable. At one level this is simply a matter of classifications-in this case, of institutions. But in taking the step from national accounts to a SAM some extra effort is obviously needed. At the same time policy makers are concerned about income distribution and considerable effort is therefore going into data collection in this field. In our approach there is no conflict between the two competing claims: the extra costs of bringing income distribution into the major macro-economic statistical picture are relatively small, and there seems to be a much wider interest in the product when households are disaggregated, rather than being treated as a single sector.

If only by reductio ad absurdum, our Swaziland study makes the fairly obvious point that it is not easy to include a disaggregated household sector unless a multi-purpose household survey-covering income received as well as expenditures-is available. Even then the problems of data reconciliation are considerable in our experience, and this is confirmed by the work of Altimir. ${ }^{46}$ It is interesting to query whether the problems exposed imply margins of error hitherto unsuspected in survey research or in national accounts. Either way, the interests of better data are well served by the discipline of trying to reconcile household surveys and national accounts.

\footnotetext{
${ }^{44}$ For the most part the techniques used in this work are discussed in Round (1976).

${ }^{45}$ As previously noted (footnote 34 ), research, is proceeding in this direction.

${ }^{46}$ See Altimir (1975).
} 
It is not entirely adequate to resolve this question in favour of national accounts data on the grounds that the savings behaviour measured by household surveys often implies that the rich dissave. In none of the case studies which we have conducted is there even approximate empirical support for the logical certainty that savings equals investment. This implied inaccuracy of data is not a trivial matter. As Ahluwalii and ihenery have emphasize $\mathrm{d}^{\text {t7 }}$, savings behaviour plays a crucial role in tw.h growth and redistribution. There is no escaping the fact that this sensitive area has hardly begun to be charted by statisticians in developing countries. ${ }^{48}$ Meanwhile, since policy never waits, a SAM approach at least forces guesses to be consistent with what is more precisely known in the macro data framework.

While we realize that reference to guesstimates is unpopular in government statistical circles, the need to accept them as a part of macro-economic statistics is unavoidable. And this point goes beyond the early arguments in favour of using data from all sources to calibrate a SAM framework. As applications of our Swaziland study demonstrate, economic planning in developing countries is largely about structural change. Our view of a SAM is as concerned with the picture of future economies which might exist as it is with the initial position in which any particular economy might be. Accordingly, if statistical effort is to focus on reducing the standard errors on forecasts relating to policy alternatives, it is not at all clear that scarce resources should be devoted to more accurate estimation of the historical position. To us, not least of the virtues of the SAM approach is to make the best use of those primary sources which might happen to exist. If these need to be filid out, pro tem, by guesstimates there is nothing new in this which is attributable to the SNA except, perhaps, the relevance of the statistician's work to the policy model.

None of this is intended to detract from the importance of good basic data. But the fact is that the SAM framework is not just a statistical tool: it is also a framework for economic analysis. Work by Bell and Hazell demonstrates this point in relation to a regional development scheme. ${ }^{49}$ Also, the SAM approach is being used as a framework for exploring planning alternatives involving huge structural change in Saudi Arabia. ${ }^{50}$ The essential point, therefore, is that SAM's are not the preserve of the statistician but a potential bond in common with the economist. This, then, is the full flavour of our earlier suggestion that the heart of the SNA is an economic model. Appreciation of the origins of the SNA in the Cambridge Growth Model make this a rather obvious point.

One further point that should be exposed in the present context is the importance we attach to classifications. It can be rehearsed in relation to production activities although it extends throughout the SAM framework. The literature of development has always seen duality in production techniques as an essential element of economics. More recently the question of vintage of technology has been found to be a powerful element of economic theorizing. And we

\footnotetext{
${ }^{47}$ In Chapter 11 of Chenery et al. (1974).

${ }^{48}$ The work of Reynolds and Spellman (forthcoming) on flow of funds in Latin American countries is an interesting exception.

${ }^{49}$ See Bell and Hazell (1976).

${ }^{50}$ See Wilkes and Macieod (1975).
} 
have already referred to the link between development planning and structural change. Is it not plausible, then, that this technological dimension of production units is just as important as the goods they produce? Indeed the SNA already recognizes that separate commodity and activity accounts are needed. Once this is accepted it is simply inefficient not to ask what the most informative classification of production might be. An answer in terms of principal products does not seem to be self-evident and therefore requires some justification. Making the best use of data by choosing appropriate classifications is also important and provides another avenue for enhancing the value of what limited resources are capable of producing.

In conclusion it should be emphasized that we do not consider any of the three SAMs discussed here to represent a best data framework for the country in question or even the best use of the available data. And there are important omissions from the discussion, such as the treatment of imputed transactions and the virtues of trying to obtain complete data for a SAM given that this will involve time and effort in estimation of some small details which may be essentially irrelevant. With respect to imputed transactions, the narrow answer is that we have simply followed national conventions throughout, since our concern has been to fill out existing national accounts rather than to produce new figures $a b$ initio. But the broader answer, and the answer to questions concerning the best SAM design for a particular country, is that such questions cannot be answered without reference to a model: only a model of the economy can define the correct basis for imputation; the distinction between what is important detail and what is not; or what is the best data system to serve the needs of policy and planning. Thus in our view questions concerning the design and implementation of a data system cannot be divorced from the model such systems are intended to serve. We would prefer such models to be explicit, but this may not be essential, and a data system may need to serve more than one model. Accordingly, there may be disagreement over what is relevant detail. But, meanwhile, we do not see model construction as the primary task even though the model (or models) is ultimately preeminent. In our view progress is to be made by iterative-or better, simultaneous-attention to a priori or model considerations on the one hand and empirical measurement and calibration on the other. Enough has been written in the literature of development economics on the importance of institutional structure and dualities to justify the view that an examination of data systems in the light of such considerations may be timely. And if this point is not conceded, then it must surely be agreed that recent concern for distributional issues is sufficient justification for an attempt to measure some aspects of this dimension of an economy consistent with other continuing concerns such as the Balance of Payments or rate of investment. While we lack a fully articulated model of how all these differeme dimensions come into play in determining the actual path of development, we know enough to be sure that consistency is not, of itself, enough and that an integrated picture of interdependence in the different dimensions is required. Hence we have attempted, on the empirical side, to integrate detaile secounts for factors and households into an otherwise conventional SAM framework. Within this we have views about preferred classifications which have been touched on at various 
points in the text. But our empirical work has been circumscribed on two counts. First, it has been necessary to work largely with secondary sources which tabulate data on the basis of classifications in current use. These may or may not be ideal, which points to the second limitation, viz. the lack of a model to resolve such outstanding issues. Differences in the existing data base as well as evolving perceptions at the a priori level explain the differences in the three country studies reported here. We have not yet reached the point of wanting to prescribe what data ought to be collected in the future and how it ought to be arranged. Thus potential conflicts between country data systems and international standards for comparability are not finally resolved in our perspective. Simply, this paper attempts to set out details of the directions in which our research has been leading, and to demonstrate the empirical feasibility of going beyond existing national accounts in three specific cases towards something more interesting and useful for policy purposes.

\section{REFHRENCES}

Altimir, O., 1975. Income Distribution Estimates from Household Surveys and Population Censuses in Latin America: An Assessment of Reliability. Economic Commıssion for Latin America and Development Research Center, World Bank (Mimeograph).

Bacharach, M. O. L., 1970. Biproportionate Matrices and Input-Output Change. Cambridge University Press.

Barkay, R. M., 1975. National Accounting di a Planning Tool in Less Developed Countries: Lessons of E.perience, Revew of Income and Wealth, Series 21, Number 4, pp. 349-370.

Bell, C. L. G. and Hazell, P. B. R., 1976. A Prcliminary Analysis of the Muda Irrigation Scheme, World Bank Development Research Center Working Paper.

Blitzer, C. R., Clark, P., and Taylor, L., 1975. Economy-wide Models and Developing Planning. Oxford University Press.

Byron. R. lforthcomingl. "The Estimation of Large Social Accounting Matrices," Journal of the Royal Statistical Society, Series A.

Cambridge, D. A. E., 1962. A Programme for Growth, Chapman and Hall. Volumes 1 to XI.

Ceylon, Central Bank, 1971. Annual Report. Central Bank of Ceylon, Colombo.

Ceylon, Department of Census and Statistics, 1971. Preliminary Report on the Socio-economic Survey of Ceylon, 1969-70), Colombo.

Ceylon, Department of Census and Statistics, 1973. National Accounts 1970), Colombo.

Chenery, H., et al., 1974. Redistribution with Growth. Oxford University Press.

Frank, C. R., 1967, The Seers Modified Input-Output Table: Some Projection Techniques, Center Paper No. 112, Yale University, Economic Growth Center, New Haven Connecticut.

Internatiunal Labour Office, 1970. Towards Full Employment: A Programme for Colombia, Geneva.

International Labour Office, 1971. Matching Employment Opportunities and Expectations: A Programme of Action for Ceylon. Volumes I and II, Geneva.

International Labour Office, 1973a. Emplnyment and Income Policies for Iran. Geneva.

International Labour Office, 1973b. Strategies for Employment Promotion: An Evaluation of Four Interagency Fmployment Missions. Geneva.

International I abour Office, 1177. Employment, Growth and Basic Needs: A Onc-11'orld Problem. Geneva.

Maliyyia, Department of Statistics, 1976. Input-Output Tables Peninsular Malaysia 1970. Kuala Lumpur.

Narapalasingham. S., 1970). On the Construction and Implementation of a Planning Model for Ceylon. Ph.D. thesis, I Iniversity of Bristol.

Pyatt, (i. with Bharier, J., Lindley, R. M., Mabro, R., and Sabolo, Y., 1972. Methodology for Macroeconomic Projections. 1L.O, (Seneva (Mlimengraph).

Pyatt, (i., and Thorbeckic, E.., 1976. Plamming Techniques for a Better Future. ILO, Geneva.

Pyitl, G. and Roe, A. R., with I indley. R. M.. Round, J. I. and others (forthcoming). Social Accouning for Development Planning with Special Reference to Sri Lanka. Cambridge University Press, Cambridge.

Pyatt. G. and Thorbecke, E. (forthcoming). Planning for Growth, Redistribution and Employment. 
Reynolds, C. W. and Spellman, L. J. (forthcoming). Financial Intermediation and Economic Development as seen through the Flow of Funds Accounts. Working Draft (Jan. 1975), Food Research Institute, Stanford University.

Round, J. I., 1976. Production, Income and Expenditure Multipliers for Peninsular Malaysia 1970: A Preliminary Analysis. Development Research Center, World Bank, Washington, D.C.

Seers, D., 1975, The Structure, Content and Uses of the Revised SNA, in the Light of the Requirements and Circumstances of Developing Countries. Interregional Serninar on the Revised System of National Accounts, U.N. Statistical Office, New York (Mimeograph).

Sen, A. K., 1973. On Economic Inequality. Oxford Clarendon Press.

Thorbecke, E. and Sengupta, J. K., 1972. A Consistency Framework for Emr'oyment, Output and Income Distribution Projections Applied to Colombia. Development Research Center, World Bank, Washington, D. C. (Mimeograph).

United Nations, 1968. A System of National Accounts, Series F., No. 2, Rev. 3. New York.

United Nations, 1975. Towards a System of Social and Demographic Statistics, Series F, No. 18. New York.

United Nations, 1977. Provisional Guidelines on Statistics on the Distribution of Income, Consumption and Accumulation, Series M, No. 61. New York.

Wilkes, D. and McLeod, R., 1975. "Modelling the Saudi Arabian Economy." Coopers Joumal, No. 24, Coopers \& Lybrand Limited, London. 